MONOGRÁFICO

Retos en la Educación Musical

para el siglo XXI

\title{
EL DESEMPEÑO DOCENTE EN EDUCACIÓN MUSICAL DEL PROFESORADO GENERALISTA DE CHILE. UN ESTUDIO MIXTO EXPLORATORIO
}

\author{
Recepción: 14/09/2019 | Revisión: 20/10/2019 | Aceptación: 06/12/2019
}

Jesús TEJADA

Institut Universitari de la Creativitat i Innovacions Educatives. Universitat de València jesus.tejada@uv.es

\section{Tomás THAYER}

Universidad Metropolitana de Ciencias de la Educación, Chile tomasthayer@gmail.com

\section{Mario ARENAS}

Universidad de La Serena, Chile marenas@userena.cl

\begin{abstract}
Resumen: Este trabajo descriptivo-exploratorio de tipo mixto pretende describir por primera vez el desempeño del profesorado generalista en el área de Educación Musical, intentando determinar si la formación musical que han recibido influye en su práctica docente, y si esta guarda relación con la eficacia que perciben de sí mismos al impartir la asignatura. Mediante un diseño mixto de investigación, se han recogido: 1) datos cualitativos mediante grupo de discusión con seis profesoras generalistas que imparten la asignatura de Educación Musical en centros educativos chilenos; 2) datos cuantitativos relativos al perfil profesional con relación a la educación musical mediante un cuestionario en línea $(n=57)$. Los resultados evidencian problemas en el desempeño de estos profesores: intervenciones de aula asistemáticas, ausencia de progresión y carencia de foco en las acciones didácticas. Una formación inadecuada o inexistente y la falta de recursos para el desarrollo de la asignatura son los principales factores de influencia en el nivel percibido de autoeficacia y en la valoración de su desempeño profesional en esta área.
\end{abstract}

Palabras clave: Educación Musical; desempeño docente; profesorado generalista; Educación Primaria; formación inicial docente.

IN-SERVICE MUSICTEACHING PERFORMANCE OF CHILEAN GENERALISTTEACHERS. A MIXEDMETHODS EXPLORATORY STUDY

Abstract: This mixed-design descriptive work seeks to describe for the first time the performance of general teachers in the area of Music Education, trying to determine if the musical training they have received in their careers influences their teaching practice, and if this is related to the effectiveness that they perceive of themselves when teaching Music. Through a mixed-methods research design, qualitative data was collected through a discussion group with six in-service generalist teachers teaching Music. An online questionnaire $(n=57)$ collected quantitative data related to their professional profile in relation to Music Education. The results show problems in the teachers' performance: unsystematic classroom interventions, lack of progression and absence of focus on didactic actions. Inadequate or non-existent pre-service music training and lack of resources for the development of the subject are the main factors influencing the perceived level of self-efficacy and the assessment of their professional performance in this area.

Keywords: Music Education, teacher performance; general teachers; Primary Education; pre-service teacher training.

\section{LATASCA DOCENT EN EDUCACIÓ MUSICAL DEL PROFESSORAT GENERALISTA DE XILE. UN ESTUDI MIXT EXPLORATORI}

Resum: Aquest treball descriptiu-exploratori de tipus mixt pretén descriure per primera vegada la tasca del professorat generalista a l'àrea d'Educació Musical, intentant determinar si la formació musical que han rebut influeix en la seva pràctica docent, i si aquesta té relació amb léficàcia que perceben de si mateixos en impartir l'assignatura. Mitjançant un disseny mixt de recerca, s'han recollit: 1) dades qualitatives mitjançant grup de discussió amb sis professores generalistes que ensenyen lassignatura d'Educació Musical en centres educatius xilens; 2) dades quantitatives relatives al perfil professional en relació a l'Educació Musical mitjançant un qüestionari en línia $(n=57)$. Els resultats evidencien problemes en la tasca d'aquests professors: intervencions d'aula asistemàtiques, absència de progressió i manca de focus en les accions didàctiques. Una formació inadequada o inexistent i la manca de recursos per al desenvolupament de l'assignatura són els principals factors d'influència en el nivell percebut d'autoeficàcia $i$ en la valoració de la seva tasca professional en aquesta àrea.

Paraules clau: Educació Musical; tasca docent; professorat generalista; Educació Primària; formació inicial docent. 


\section{Introducción}

La Educación Musical fomenta la creatividad y el pensamiento crítico y, por tanto, contribuye a un desarrollo integral de las personas (Abrahams, 2005; Regelski, 2005). El arte en la escuela facilita la reinterpretación de la realidad en base a un sistema de pensamiento que no otorgan otras áreas del currículo (Efland, 2004; Eisner, 2002). Por ello, debe visibilizarse cuál es el lugar de la Educación Musical en la escuela y después conocer su función en el currículo escolar (de Vries, 2011; Sepúlveda, 2014).

Sin embargo, las políticas educativas no parecen reconocer el importante rol de las asignaturas que constituyen el área artística, situándolas de facto como disciplinas marginales. Esto tiene consecuencias en la formación inicial musical del profesorado generalista, tal como se evidenciará en las siguientes páginas. De los documentos oficiales, se desprende la incongruencia entre el "desarrollo integral" asignado como objetivo de la educación artística en la enseñanza básica por el propio Ministro de Educación (Ministerio de Educación de Chile, 2012a, p. 5) y el hecho de que la Educación Musical no sea una materia evaluable en el Sistema de Medida de Calidad de la Educación, más coloquialmente prueba SIMCE (Agencia de Calidad de la Educación, 2018). Esta prueba obligatoria de ámbito nacional que se aplica en Educación General Básica (EGB) y Educa-ción Media trata de medir la calidad de los aprendizajes escolares. Sin embargo, quedan fuera de evaluación los conocimientos construidos mediante las materias artísticas, lo cual constituye un contrasentido.

El profesorado es muy importante ya que se responsabiliza de la formación de niños y niñas y se constituye en agentes sociales que determinan el lugar que ocupa la música y las artes en la cultura escolar; conforman desde la educación obligatoria la construcción de saberes culturales de la sociedad en general (Orbeta-Green y Oyanedel-Frugone, 2018). Esta manifestación es asumida por el Ministro de Educación de Chile en el Preámbulo de las Bases Curriculares de EGB (Ministerio de Educación de Chile, 2012a, p. 5). La tarea de impartir música en los dos primeros ciclos de EGB se ha encargado a profesores generalistas, dado que por normativa el profesorado especialista de Música sólo está habilitado para impartir educación musical en la Educación Media. A pesar de que el profesorado de EGB tiene que impartir Educación Musical, el documento de Estándares Orientadores para Egresados de Carreras de Pedagogía en EGB no incluye ninguna competencia relacionada con dicha área (Ministerio de Educación de Chile, 2012b). Se produce así una tensión multidimensional que afecta a las pretensiones del Ministerio, la decisión sobre el profesorado que debe impartir educación musical, las competencias que el profesorado debe desarrollar y los conocimientos que niños y niñas deben construir. Además, estos problemas coexisten con un déficit general de recursos para impartir la materia, problema emergente de los resultados de este trabajo confirmados en varios trabajos (Ángel-Alvarado y Lira-Cerda, 2017; UNESCO, 2009)

El análisis documental de los planes de estudio de Pedagogía en EGB que realiza ÁngelAlvarado (2018a) en 39 instituciones chilenas de Educación Superior muestra que 11 de las 39 carreras analizadas dotan de formación completa en relación a las bases curriculares de Música para la Educación General Básica; 13 carreras la abordan parcialmente, bien desde la percepción (5) o desde la expresión (8). Otras 2 carreras abordan la Educación Musical en espacios compartidos 
con Educación Física o con Artes Visuales, y 12 carreras no aportan información en sus planes de Pedagogía en EGB. Por último, 3 planes de estudios no incluyen ningún tipo de formación musical. Los datos de este trabajo sugieren que existe una oferta formativa insuficiente en Educación Musical en Pedagogía en EGB y que no parece existir una voluntad por parte de las universidades para solventarla. Esta renuencia a incorporar la Educación Musical en los planes de formación inicial del profesorado de EGB tensiona el perfil de egreso respecto a las competencias músico-pedagógicas que el profesorado debe construir en la escuela según el ordenamiento legal vigente y dan mayor importancia a las materias que permiten el desarrollo de las competencias evaluables en la prueba de evaluación del profesorado en formación (Evaluación Nacional Diagnóstica; END).

Otro estudio reciente aborda este mismo problema en la educación artística (OrbetaGreen y Oyanedel-Frugone, 2018). El trabajo analiza documentalmente la inclusión de las enseñanzas artísticas en 49 programas de Pedagogía en EGB de 44 instituciones chilenas de educación superior, triangulando y complementando resultados con 10 estudios de caso. Los resultados muestran que solo la mitad de las universidades dotan de cursos suficientes de enseñanza artística, sea disciplinar y/o didáctica. Sugieren que el profesorado carece de formación artística en su formación inicial.

El Ministerio de Educación de Chile (2017) establece la prueba END, mencionada anteriormente, que se administra en el penúltimo año de carrera de la formación inicial del profesorado y que valora el conocimiento pedagógico, la madurez intelectual y el conocimiento disciplinar. La END sería un instrumento válido para monitorizar el nivel de cumplimiento de las universidades respecto a la consecución del perfil de egreso para Pedagogía en EGB y a su armonización con las competencias músico-pedagógicas necesarias en la escuela. No obstante, ninguna de las áreas artísticas es evaluada en esta prueba. Ello evidencia la escasa consideración hacia las competencias músico-pedagógicas que construye el profesorado durante su carrera y, por ende, hacia la educación artística en el currículo escolar. La formación continua, una fuerza de consolidación y actualización científico-técnica del profesorado, es escasa o inadecuada en la educación musical chilena.

En relación a estas inconsistencias, la formación musical inicial es uno de los factores de importancia en la percepción de autoeficacia para la docencia de música por el profesorado generalista. Este se siente incapaz de dar clases de Educación Musical en sus aulas (Alter, Hays y O'Hara, 2009; de Vries, 2011, 2013; Hallam et al., 2009; Holden y Burton, 2006; Oreck, 2004). Esta actitud negativa se deriva de una falta de confianza o de autoeficacia hacia la enseñanza de la música (Garvis, 2013; Gifford, 1993; Jeanneret, 1997).

En el debate sobre la conveniencia de que la música sea abordada por generalistas o especialistas, Holden y Burton (2006) proponen que sean especialistas, mientras que Mills (1989) advierte de su inadecuación en los primeros años de escolarización. Según Mills, la existencia de especialistas no necesariamente mejora la educación musical: los niños valoran menos una materia que es impartida por una persona diferente a su tutora. Russell-Bowie (2011) ha sugerido una tercera vía: el uso de un supervisor o supervisora, quien podría proporcionar a los generalistas que enseñan música demostraciones didácticas prácticas que pueden influir fuertemente en 
la autopercepción de eficacia. En este mismo sentido, el profesorado universitario que imparte Educación Musical en la formación inicial podría constituir un fuerte factor de influencia en las representaciones que tiene el profesorado generalista sobre su eficacia (Bautista, 2017).

Este trabajo pretende describir las prácticas docentes del profesorado generalista en el área de Educación Musical, intentando determinar si la formación musical que han recibido influye en su práctica docente y si esta guarda relación con la eficacia que perciben de sí mismos al impartir la asignatura.

\section{Método}

Dado que este trabajo es el primero que se realiza sobre este tema, al menos de acuerdo a la bibliografía consultada, se consideró un diseño exploratorio-descriptivo de tipo mixto. Para alcanzar los objetivos pretendidos, se ha recogido dos conjuntos de datos: 1) datos cualitativos sobre las percepciones de un grupo de profesoras generalistas de la Región Metropolitana de Santiago de Chile, mediante la técnica de grupo de discusión; 2) datos cuantitativos a través de la administración de un cuestionario online de 41 ítems que han completado docentes generalistas de diferentes regiones y comunas de Chile. Todos imparten Educación Musical en los dos primeros ciclos de EGB.

Con una muestra carente de representatividad de la población, el estudio no pretende obtener validez externa; por tanto, los resultados de investigación no pueden extrapolarse a la población objeto de estudio y su interpretación debe tratarse de manera contextualizada. El interés de este estudio en utilizar una mezcla de datos cualitativos y cuantitativos es generar una complementariedad informativa que permita no solo comprender los fenómenos estudiados dentro de una comunidad limitada de personas, sino también dar credibilidad a los datos mediante una adecuada triangulación con datos cuantitativos que faciliten una interpretación menos sesgada del equipo de investigación.

Para el procedimiento ético, se obtuvo la autorización del Comité de Ética de la Universidad de La Serena, Chile, quien sancionó el protocolo ético a seguir, los documentos necesarios de consentimiento y retracto de las participantes y se aseguró el uso privado de los datos personales y el acceso al informe final del trabajo. Se exponen por separado los datos obtenidos con cada uno de los instrumentos.

\section{Estudio cuantitativo}

\subsection{Participantes}

Los participantes fueron reclutados de modo aleatorio. Se realizó mediante dos procedimientos: 1) a través de solicitud en web mediante redes sociales de profesorado chileno; 2) mediante correos electrónicos directos a todos los egresados de la Universidad Metropolitana de Ciencias de la Educación, en Santiago de Chile en las últimas 10 cohortes. El criterio para participar en la encuesta fue pertenecer al colectivo de profesorado de EGB, o bien al profesorado especialista de cualquier área curricular excepto Educación Musical. Respondieron un total de 99 personas. 42 casos fueron retirados del análisis de datos de este estudio porque fueron profesorado de Edu- 
cación Musical, no ajustándose al criterio de inclusión. No se estableció un número mínimo de cuestionarios a procesar, resultando 57 cuestionarios válidos procedentes de profesorado de EGB en diferentes regiones chilenas, una muestra no representativa de la población.

\subsection{Instrumentos y validación}

Se empleó un cuestionario que incluyó 50 ítems clasificados en 5 escalas de medida:

1) Datos profesionales y demográficos (12 ítems).

2) Formación y necesidades formativas en educación musical (11 ítems);

3) Recursos musicales en centro educacional y uso en aula (4 ítems);

4) Praxis docente en educación musical (16 ítems);

5) Formación tecnológica (7 ítems); el análisis de estos datos no ha sido presentado aquí porque no es pertinente con el tema del trabajo.

Las respuestas a los ítems fueron de tres tipos: dicotómicas, ordinales y abiertas. Dos investigadoras de la Universidad Metropolitana de Ciencias de la Educación, en Santiago de Chile, realizaron la validación del cuestionario utilizando como criterio la adecuación de cada ítem al objetivo de la investigación. Las jueces respondieron con respuesta dicotómica SÍ-NO a la pregunta sobre adecuación de cada ítem. Además, se incluyeron respuestas abiertas para indicar sugerencias a cada ítem y cada sección, la presentación general, la extensión y el orden de los ítems en el instrumento. Las observaciones y sugerencias de los jueces en la primera evaluación del instrumento fueron utilizadas para modificar el cuestionario. Después, se realizó una segunda evaluación del instrumento modificado.

Se utilizó el coeficiente kappa de Cohen como el estadístico que midió el acuerdo entre observadores (Torres y Perera, 2009), resultando un valor $(\kappa)$ de fuerza considerable $(\kappa=0,79)$. El cuestionario fue difundido a través de tres redes profesionales de profesorado y de la oficina de egresados de la Universidad Metropolitana de Ciencias de la Educación (Santiago, Chile). El período de difusión fue de 6 meses a través de la plataforma Jotform (https://www.jotform.com).

\subsection{Resultados}

Como se mencionó en la sección Método, los resultados expresados a continuación no permiten ser generalizados a la comunidad de profesorado de EGB en Chile, dado que no existe representatividad de la muestra, por lo que deben ser interpretados junto a su discusión en el contexto de una realidad particular.

\subsubsection{Perfil socio-profesional}

Respondieron a la encuesta 42 profesoras y 15 profesores. La mayoría del profesorado es joven: un 58\% está situado en el rango 20-40 años de edad. 54 personas tienen una Licenciatura y tres tienen un Magister. Respecto a las titulaciones profesionales, el 61\% es profesorado de EGB, el 19\% especialistas en Matemáticas, el 9\% especialistas en Lenguaje y Comunicación y el resto son especialistas en otras áreas curriculares (Ciencias, Informática, Educación Diferencial, Historia). Dichas titulaciones se han cursado mayoritariamente en la capital (Universidad Metropolitana de 
Ciencias de la Educación, 49\% y Pontificia Universidad Católica, 9\%). El resto (42\%) corresponde a universidades de otras regiones del país.

La experiencia docente es muy variada. El $70 \%$ del profesorado tiene una experiencia entre 1 y 15 años, siendo la moda el rango 1-5. Casi el 60\% de las personas encuestadas imparten Educación Musical en sus centros, que se sitúan principalmente en ciudades de la Región Metropolitana de Santiago (58\%), Región de Valparaíso (14\%) y Región de Antofagasta (9\%). El resto, en proporciones menores, en otras ciudades del país. Los centros donde trabajan son particulares subvencionados (57\%), municipales (40\%) y particulares (2\%). Las ratios de alumnos/profesor más numerosas oscilan en los intervalos 16-25 y 41-45 alumnos, compartiendo la moda tres intervalos: 26-30, 31-35 y 36-40, con nueve casos en cada uno.

\subsubsection{Formación musical y requerimientos didácticos específicos}

El 51\% de las personas encuestadas manifiestan haber tenido experiencias musicales previas a la carrera. Son en su mayoría actividades de canto coral y de estudios musicales no reglados (profesores particulares; Figura 1).

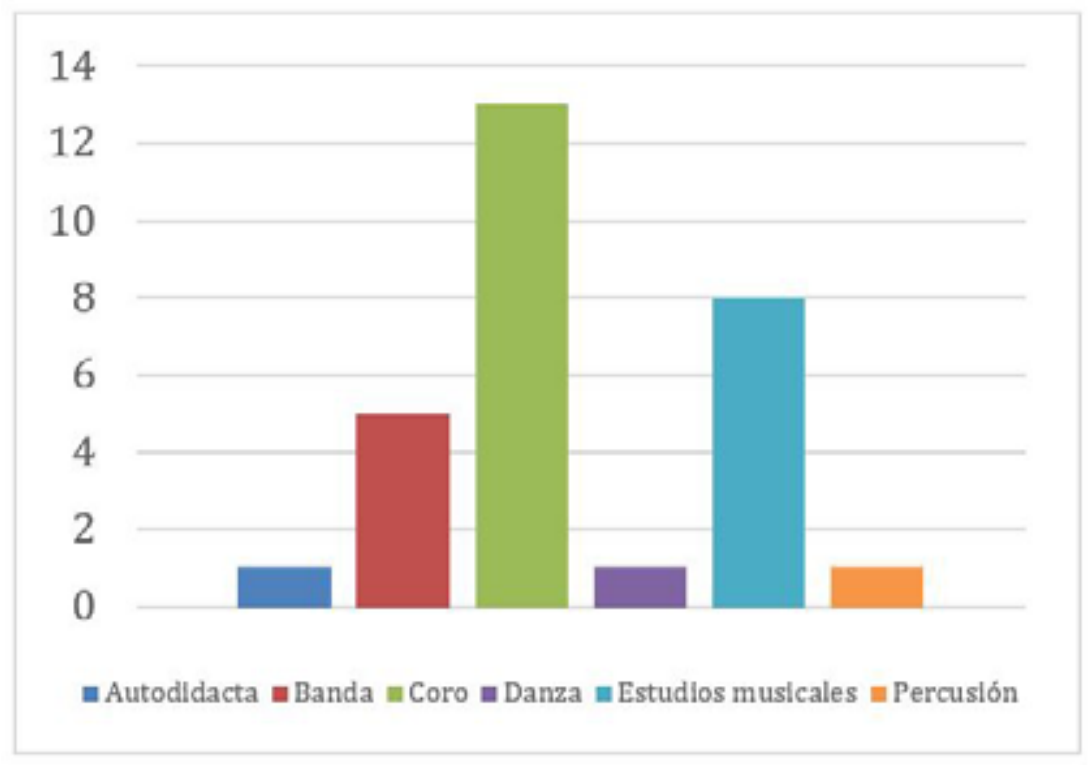

Figura 1.Tipos de experiencias musicales previas a cursar la carrera de Pedagogía en EGB.

El 38\% del profesorado manifiesta haber realizado cursos de formación musical en el plan de estudios de su carrera, mientras que el $42 \%$ declara no haber recibido. Las materias cursadas son muy diversas, siendo las de mayor incidencia Solfeo e Instrumento (área formativa musical) y Didáctica de la Música (área pedagógica). En menor grado, materias relacionadas con el Folclore. En cuanto a la formación continua, responden 9 personas (16\%) (Tabla 1). Tan solo 2 de ellas han realizado cursos de perfeccionamiento a través del CPEIP. ${ }^{1}$

1 El Centro de Perfeccionamiento, Experimentación e Investigaciones Pedagógicas (CPEIP) es una agencia gubernamental dependiente del Ministerio de Educación de Chile que tiene como misión "fortalecer la formación inicial y apoyar el desarrollo de educadores, profesores y directivos a lo largo de toda su vida profesional” (https://www.cpeip.cl/mision-vision/). 


\begin{tabular}{|c|c|c|}
\hline Cursos & Casos & \% \\
\hline coro & 1 & 3,8 \\
\hline danza & 2 & 3,5 \\
\hline didáctica & 2 & 3,5 \\
\hline perfeccionamiento CPEIP & 2 & 1,8 \\
\hline producción musical & 1 & 1,8 \\
\hline teoría & 1 & 84,2 \\
\hline NC & 48 & 100,0 \\
\hline Total & 57 & \\
\hline
\end{tabular}

Tabla 1. Cursos de perfeccionamiento realizados (NC: no contesta al ítem).

El 75\% opina que no existe una oferta de formación continua que responda a sus intereses. En el último ítem de esta sección, de tipo abierto, se solicita opinión sobre los tipos de cursos que les interesaría y responden con: cursos de formación musical (16\%), cursos de formación pedagógica (35\%) y ambos (35\%) (Figura 2).

El 67\% de las personas encuestadas afirman que el sostenedor ${ }^{2}$ no les facilita el tiempo para su formación continua. Esto datos se correlacionan con los del ítem que pregunta si el sostenedor del establecimiento incluye o no el tiempo de formación continua dentro de la jornada de trabajo del profesorado (23\% lo incluye y $75 \%$ no lo incluye). Asimismo, se correlacionan con el apoyo económico que el sostenedor aporta al perfeccionamiento docente, un $21 \%$, frente al $79 \%$ que no lo hacen.

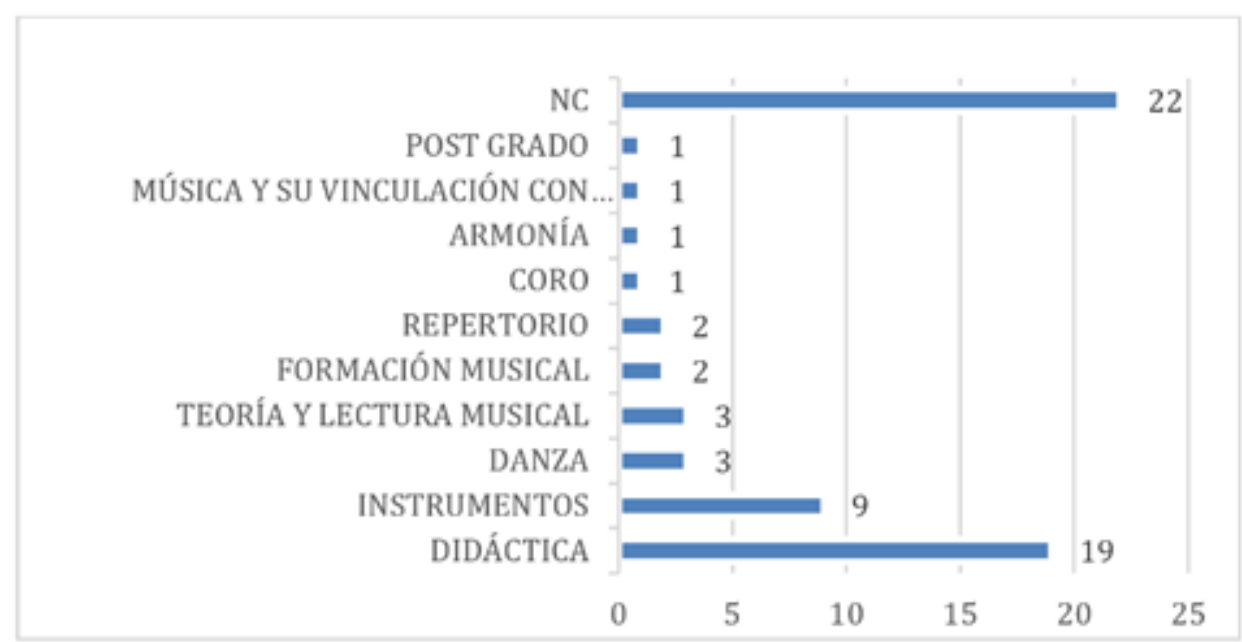

Figura 2. Sugerencias de cursos de formación continua realizadas por el profesorado (NC: no contesta al ítem).

2 En Chile, el sostenedor de un colegio es la persona que aporta los recursos económicos. Puede ser una institución pública (en cuyo caso, el colegio es público) o un inversor o empresa (el colegio es privado o, si recibe aportaciones del Estado o del municipio, es privado subvencionado). 


\subsubsection{Educación musical, profesorado y recursos del centro}

El número de horas semanales de música impartidas en el centro es un ítem que debería mostrar consistencia en tanto indicador del cumplimiento de la Ley de Educación. No todas las personas responden de igual forma a este ítem. Es sorprendente que un $28 \%$ responde que no hay clases de música en sus centros, mientras que el 68\% manifieste que dispone de dos horas semanales, es decir, la cantidad prescrita en el currículo para el primer ciclo de EGB. Asimismo, más de un $38 \%$ de la muestra responde que no hay especialista de Educación Musical en sus centros, ${ }^{3}$ mientras que un $60 \%$ afirma lo contrario.

El 58\% de la muestra responde que no existe una sala específica para la clase de Educación Musical en sus centros, mientras que el $40 \%$ afirma lo contrario. En cuanto a los recursos específicos, el profesorado declara utilizar frecuentemente un equipo de audio, instrumentos de música y computador. Los textos de música se utilizan con mucha menor frecuencia, así como otros recursos (pizarra, proyector de vídeo e Internet) (Figura 3).
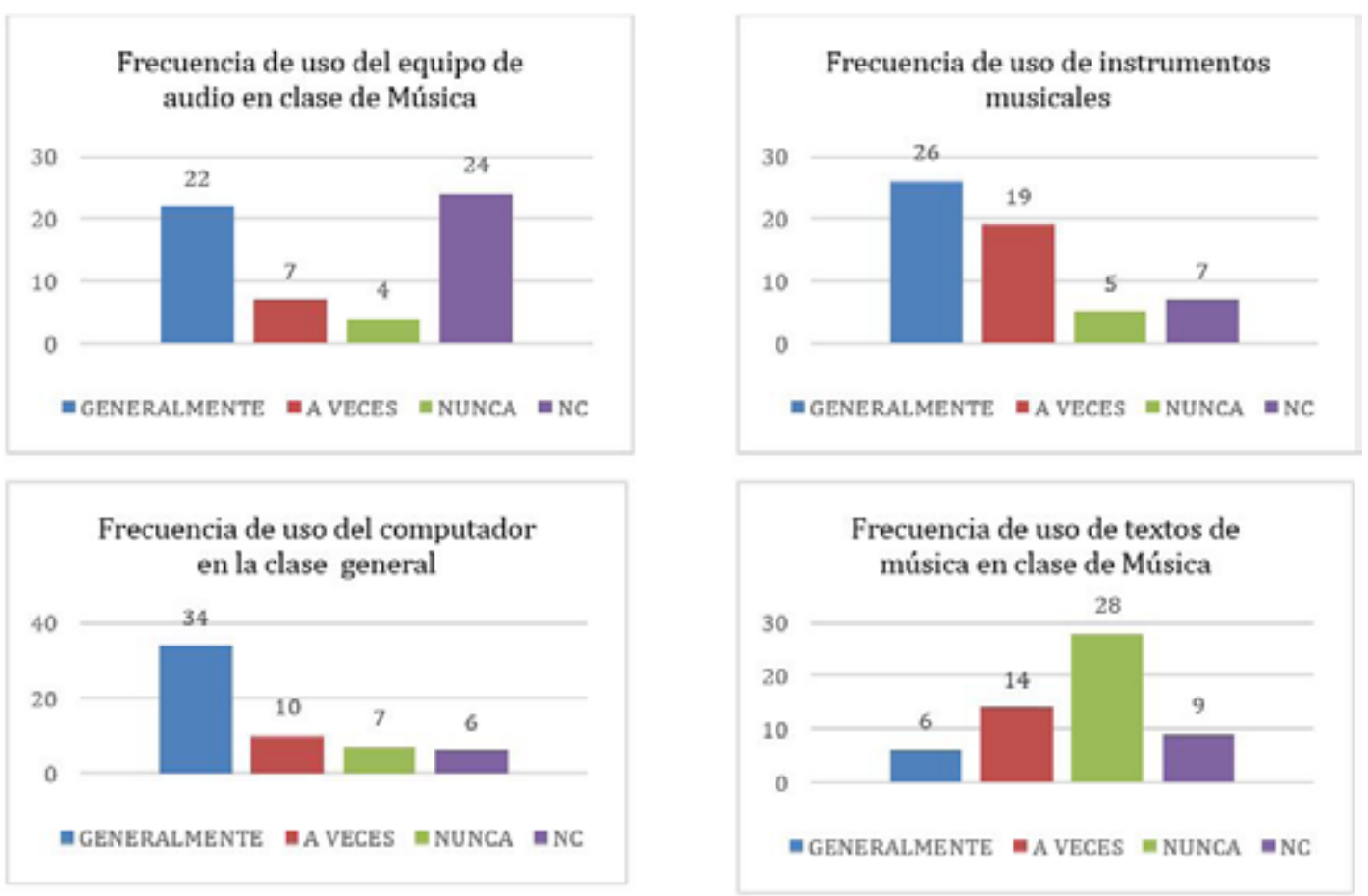

Figura 3. Frecuencia de uso de diferentes recursos en la clase general y en la de Música (NC: no contesta al ítem).

Casi un 30\% del profesorado usa computador y software para impartir clase de música. Estos declaran emplearlos en actividades de audición y para apoyar con vídeos, entre otras (Figura 4).

3 En Chile, el profesorado especialista de Ed. Musical está autorizado a impartir en Ed. Secundaria (Ed. Media). Para poder impartir en Ed. Primaria (Ed. Básica), deben solicitar una autorización expresa al Ministerio de Educación. No obstante, la habilitación no implica que satisfagan los requerimientos de la etapa en relación con las competencias pedagógicas. 


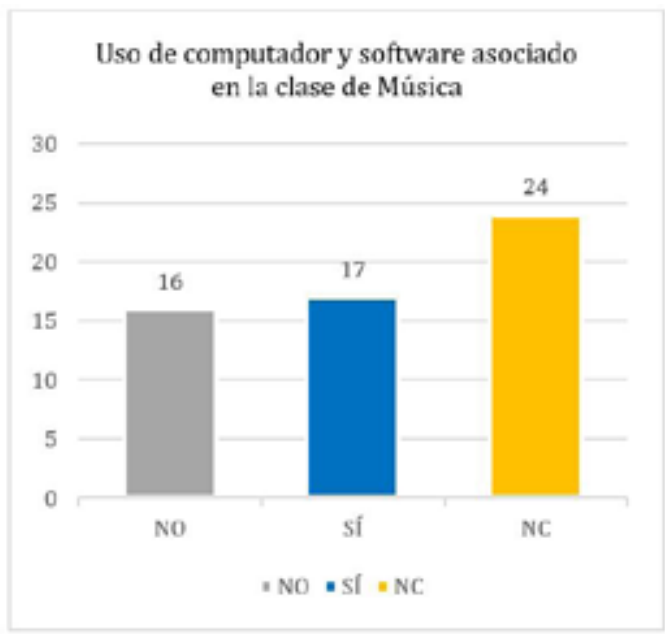

Figura 4. Uso del computador en aula y actividades realizadas

con apoyo del mismo (NC: no contesta al ítem).
Actividades realizadas con el ordenador en la clase de Música

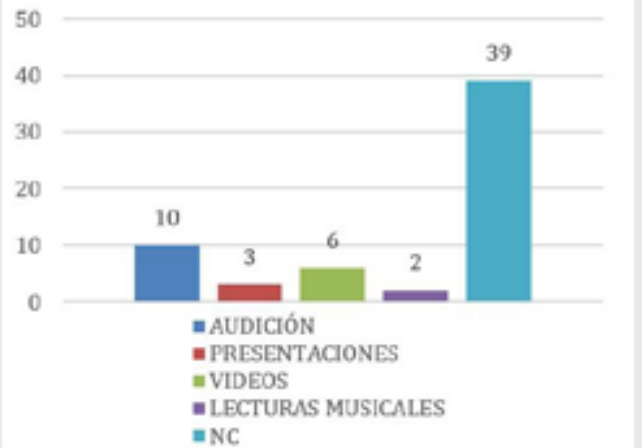

\subsubsection{Práctica docente en música}

El 63\% del profesorado no usa el programa vigente para la asignatura de música en EGB publicado por el Ministerio de Educación y constituye un resultado inesperado de la encuesta. El 37\% restante lo ha empleado en un número variable de actividades, que opina de manera muy diversa sobre su utilidad. Se registra una tendencia hacia el valor central, sesgando positivamente. Lo mismo ocurre con la valoración de las sugerencias metodológicas, siendo algo más equilibrada la valoración de sugerencias evaluación.

En relación al grado de presencia de los ejes propuestos en los programas de música del Ministerio: 1) escuchar-apreciar, 2) interpretar-crear, 3) reflexionar-contextualizar, el profesorado encuestado manifiesta implementar más en sus clases el eje escuchar-apreciar que el resto de ejes propuestos (Figura 5). Una interpretación plausible de este resultado puede ser que la formación musical recibida por el profesorado en sus carreras estuvo centrada en la escucha y apreciación, actividades "económicas" en recursos y poco obtrusivas con las infraestructuras de la universidad (por ejemplo, no es necesario reconfigurar las aulas para disponer de espacios físicos para actividades de ritmo y movimiento). 

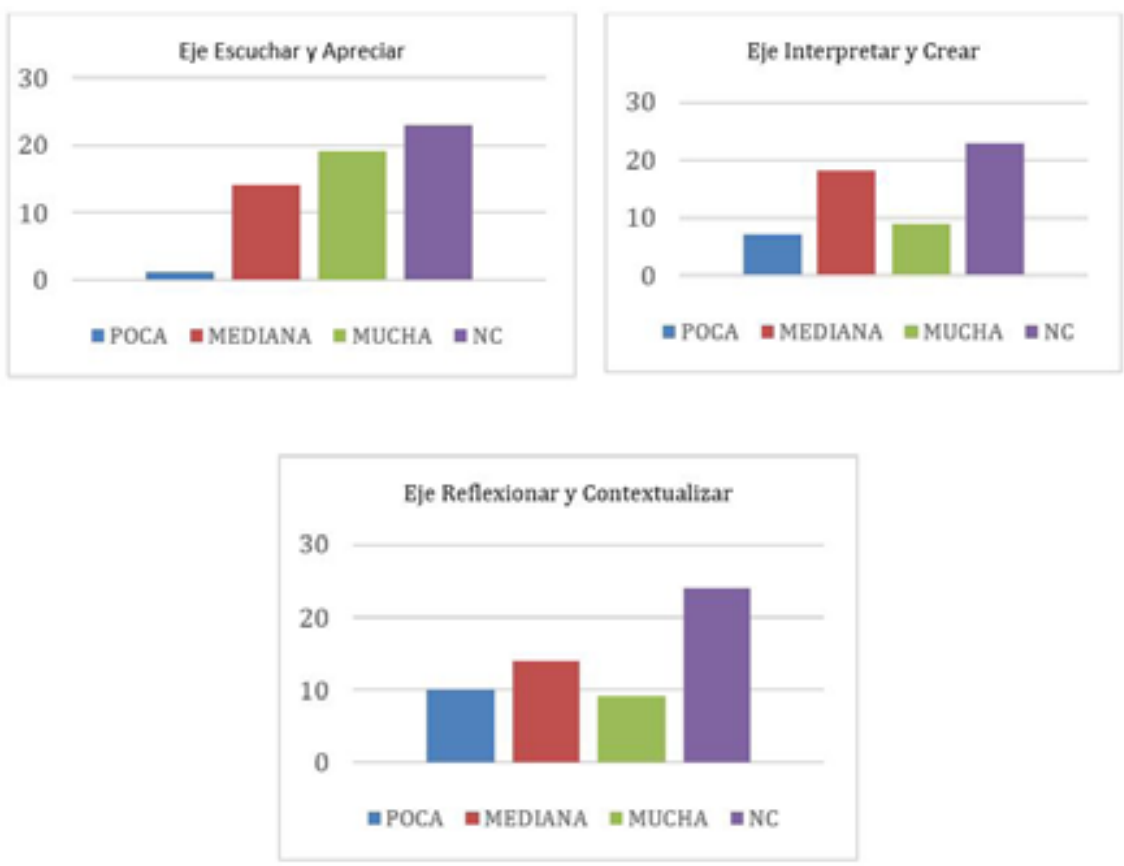

Figura 5. Presencia de los ejes del programa de música en las actividades musicales que imparte el profesorado encuestado (NC: no contesta al ítem).

En cuanto a las actividades realizadas en clase, predomina un equilibrio entre teóricas y prácticas, con una mayoría que logran una reflexión después de concluirla (Figura 6). La mayor parte de actividades provienen de iniciativas del profesor, de búsqueda en Internet o de libros. En relación a la disposición, el alumnado se adapta en función de las actividades realizadas, no siguen agrupaciones predefinidas, como filas (lo que se podría interpretar como un predominio de clases teóricas) o círculo (lo que indicaría predominio de clases prácticas).
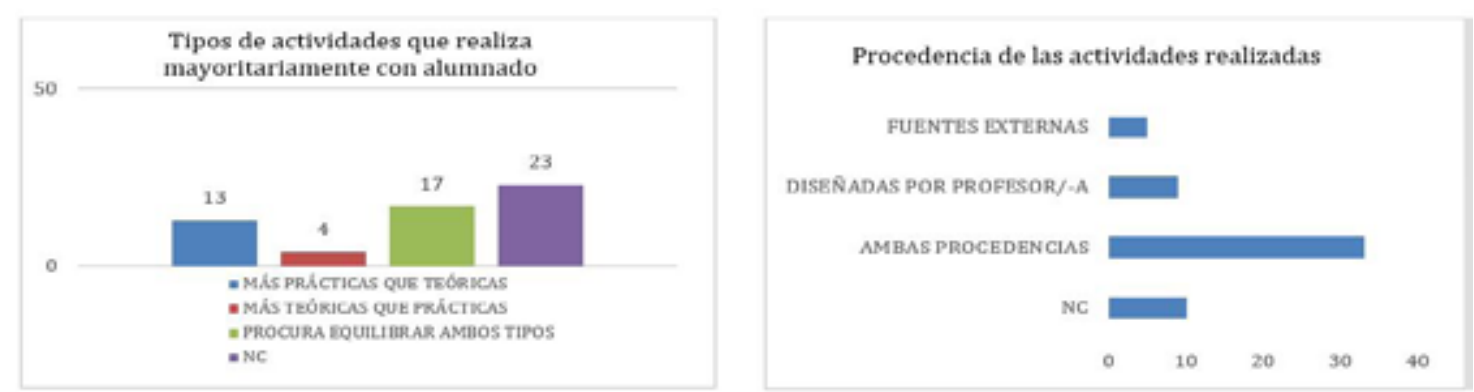

Figura 6. Tipos y procedencia de las actividades realizadas por el profesorado (NC: no contesta al ítem).

Respecto a la evaluación, el profesorado declara mayoritariamente que evalúa los aprendizajes a través de las presentaciones del alumnado (45\%). El resto no contesta, lo que conduce a la idea de que no evalúan la asignatura.

Los dos últimos ítems del cuestionario se refirieron a: 1) si les gustaba impartir música en 
EGB (dicotómico); y 2) el motivo para impartirla (ítem abierto). Las respuestas a este último ítem fueron desglosadas en los códigos que se muestran junto a las citas capturadas para codificar. El $61 \%$ respondió afirmativamente y un $27 \%$ negativamente. Se interpreta que el profesorado generalista que imparte educación musical lo hace porque realmente cree en el valor de la música (Figura 7), unas veces apoyándose en el valor intrínseco de la educación musical como disciplina y otras apoyándose en argumentos de utilidad extrínseca para otras áreas. Las personas que no imparten tienen poca confianza en sus competencias o habilidades en educación musical.

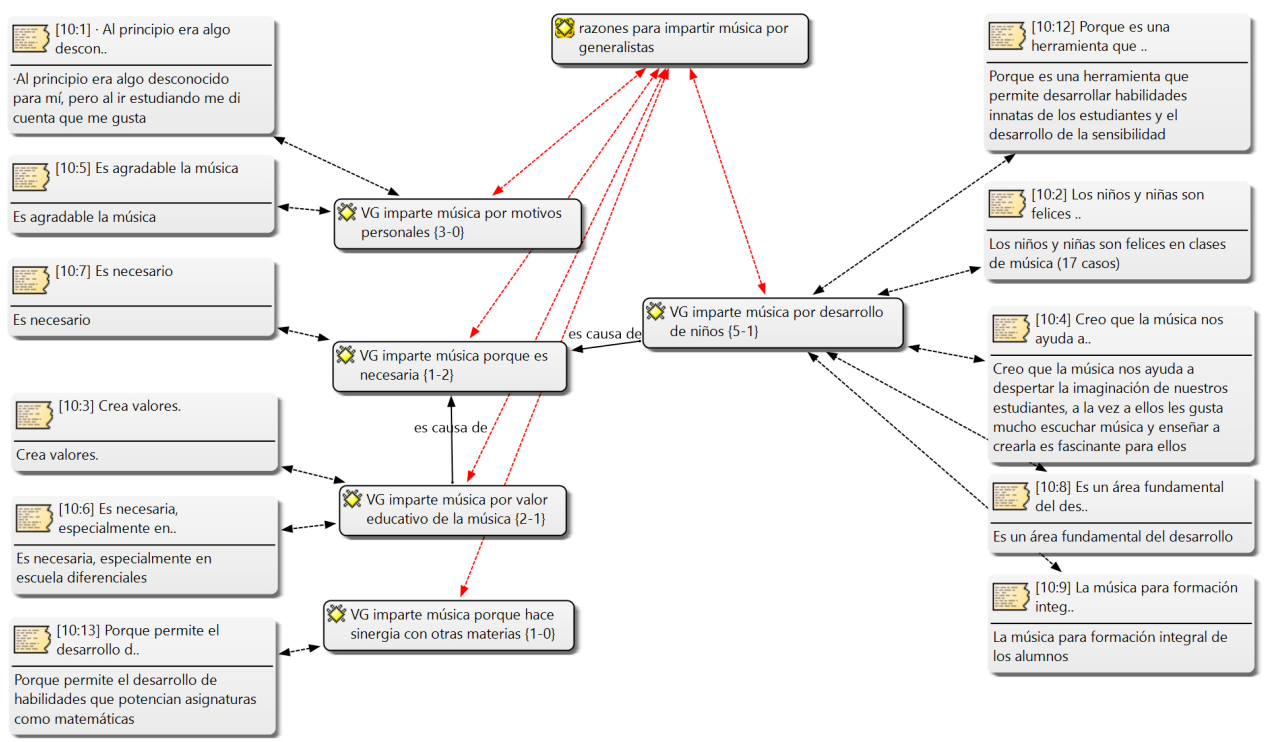

Figura 7. Códigos de agrupamiento de citas en relación a los motivos del gusto por impartir música del profesorado.

\section{Estudio cualitativo}

Se realizó un grupo de discusión en el que participaron 6 profesoras de EGB en ejercicio de la Región Metropolitana de Santiago. Fueron seleccionadas por conveniencia. Todas ellas trabajan en centros particulares subvencionados. El nivel socioeconómico de los centros es medio ( 2 centros), medio-bajo ( 2 centros) y bajo ( 2 centros). Fueron seleccionadas de acuerdo a: 1) su condición de profesoras generalistas de EGB; 2 ) declarar experiencia de haber impartido Música en dicha etapa, bien en el momento presente o en cursos pasados.

La validez del guion del grupo fue validada por dos profesoras universitarias de acuerdo a un criterio de adecuación. Además, añadieron temas pertinentes a ser tratados en el grupo focal.

\subsection{Categorías de análisis}

Se determinaron tres categorías previas: 1) formación musical, 2) currículo y praxis musical; y 3) formación continua, que permitieron obtener información sobre necesidades formativas y problemas en el aula de Música (Figura 8). Después de obtenida y transcrita la información, se re- 
alizó una selección de las unidades de significación y se realizó una codificación libre posterior mediante el software Atlas-ti. Después, los códigos libres fueron agrupados en familias y asociados a las categorías previas (Coffey y Atkinson, 2003).

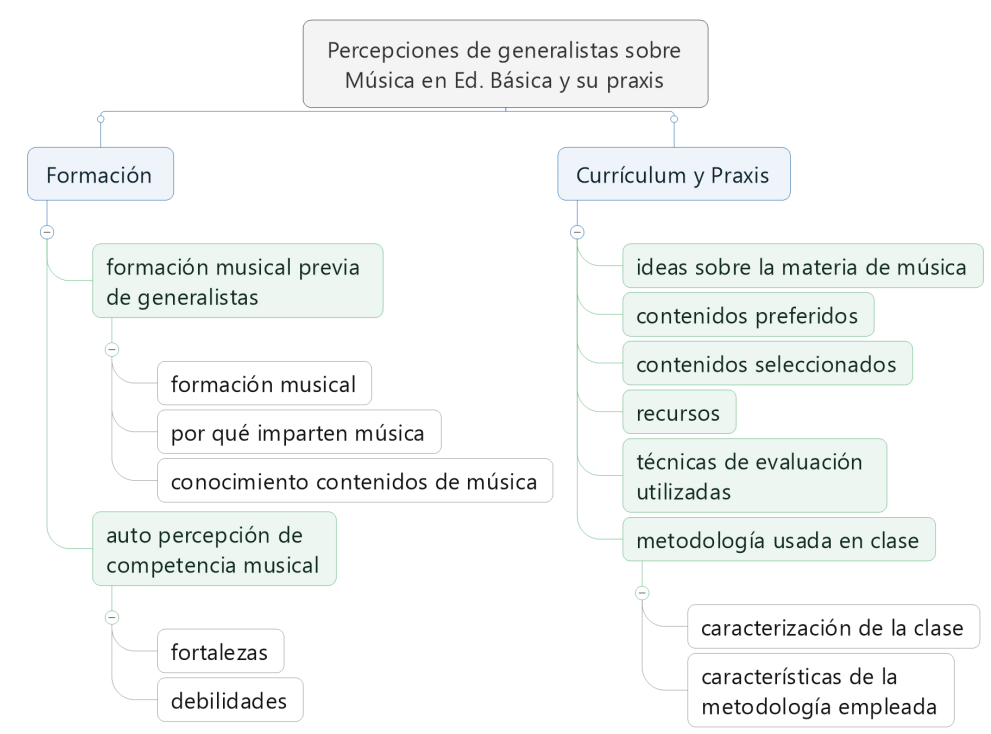

Figura 8. Temas principales planteados en la conversación y categorías analíticas.

\subsection{Procedimiento}

La moderadora se presentó ante las profesoras, recordó los objetivos generales de la investigación que les había reunido allí y manifestó los objetivos del grupo de discusión. Después de algunas preguntas para la generación de un clima de confianza, se expusieron uno a uno los temas-clave ciñéndose al guion elaborado. Se registró la información en una grabadora. El grupo de discusión tuvo una duración de 70 minutos y fue realizado en la región metropolitana de Santiago de Chile. Los datos fueron analizados de acuerdo a las categorías antes expuestas y tratados mediante el software Atlas.ti.

\subsection{Resultados}

\subsubsection{Formación musical previa y autopercepción de competencias musicales}

Las profesoras manifiestan que imparten las clases de Música en EGB por la necesidad de completar su carga horaria, en los colegios subvencionados donde trabajaban. En algunas ocasiones, los reemplazos han sido los motivos por los que han tomado las clases de música, siendo ocasionales o incluso definitivos (quedaron señaladas finalmente como profesoras de Música).

En general, las profesoras entrevistadas manifiestan que su formación musical fue escasa o nula en sus carreras. Aunque asistieron a cursos de formación musical en sus carreras, se limitó a lo más básico: aprendieron algunas canciones y obtuvieron nociones de teoría y solfeo. Declaran que sus competencias actuales de música son escasas. Algunas se sienten agobiadas al 
tener que dar clase de Música. Perciben una falta de formación musical para abordar clases de Música en EGB cuando se comparan con los especialistas.

Es probable que la representación mental de las participantes sobre contenidos de Música se vea influida por su competencia con la parte más técnica de la teoría y los instrumentos. Las maestras coinciden en su principal fortaleza como docentes: el manejo del grupo. Son conscientes de sus problemas con contenidos específicos de Educación Musical, no obstante, señalan tener experiencia en manejar grupos y disponen desarrolladas estrategias de motivación y disciplina; saben utilizar la autoridad cuando la requieren y gestionan adecuadamente las necesidades de los niños y niñas. Por último, manifiestan su resiliencia ante las dificultades que plantea la carencia de competencias musicales y reconocen su creatividad e iniciativa a la hora de buscar soluciones.

Sin embargo, exponen se interpreta una baja autopercepción de sus competencias docentes en educación musical que probablemente provienen de su formación inicial, pues mencionan lagunas de conocimientos y destrezas. El cuadro resumen de la Figura 9 resume las opiniones al respecto:

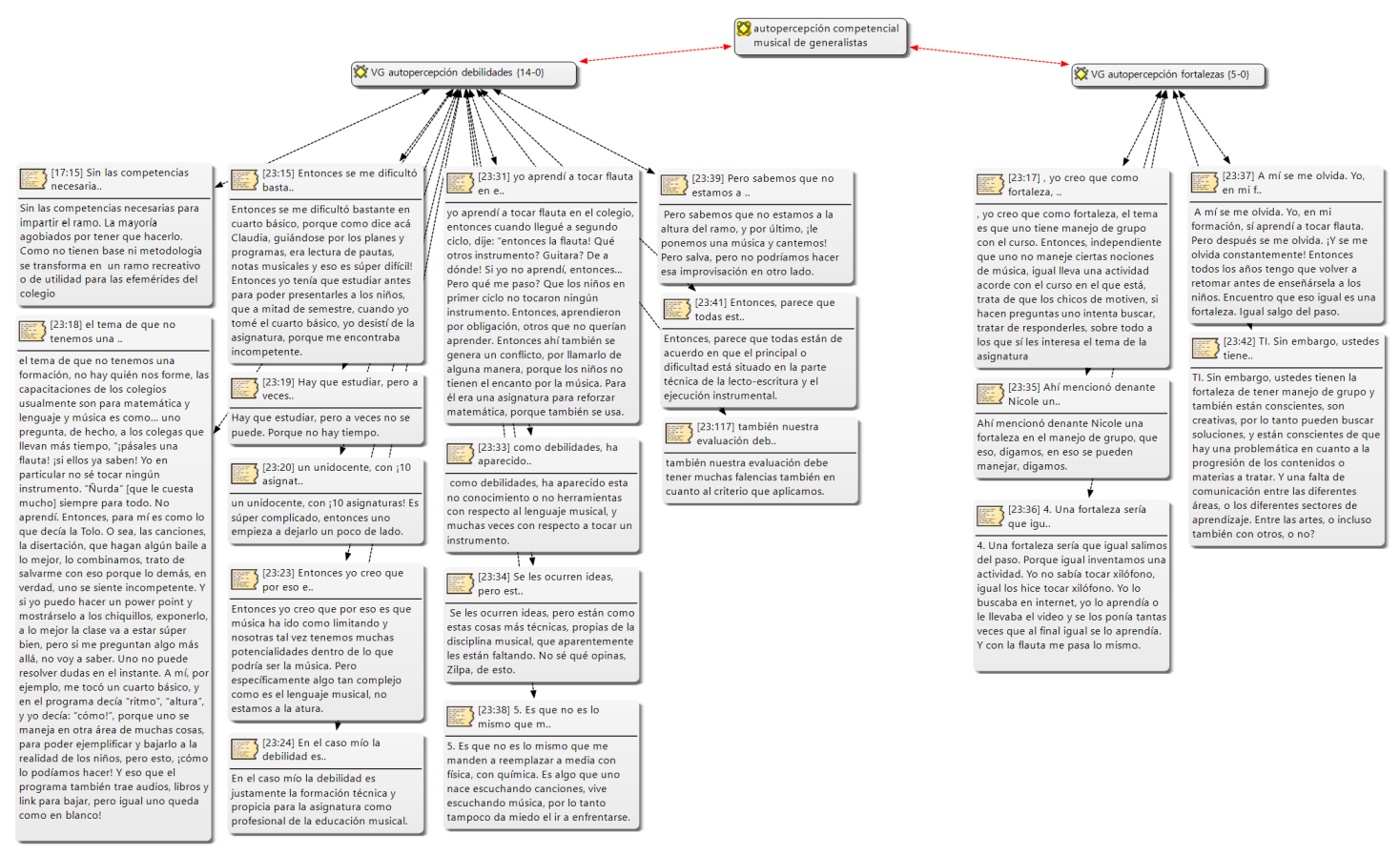

Fig. 9. Manifestaciones de las profesoras respecto a su percepción competencial en Educación Musical. 


\subsubsection{Currículum de música y práctica docente en EGB}

Las ideas sobre el currículo son muy diversas. En general, se interpreta que las participantes creen que existe desdeño del claustro de profesores de los centros escolares hacia las asignaturas artísticas. Esto llega al extremo de que los profesores de Matemáticas o de Lenguaje piden a la profesora de música horas de Música para impartir dichas materias. Esta práctica irregular se realiza al amparo de muchos sostenedores de colegios dado que son materias importantes que se evalúan en la prueba SIMCE (prueba nacional de madurez que se realiza al final de EGB). Las puntuaciones de esta prueba permiten realizar un ranking de colegios y la publicidad asociada a este indicador permite a los centros obtener más o menos matriculaciones en función de su posición en él.

[Prof.] "Siento también que hay un menosprecio también, entre las comillas, de las asignaturas artísticas. Porque si es que les faltan horas, por ejemplo, de Matemática, 'ah, ya, entonces saquémosle a arte'; 'ah, ya, pero saquémosle a Música. Ocupemos'... [...]

[Entrev.:] “¿Las horas de libre disposición?” 4

[Prof.] "No. Por ejemplo, si hay que reforzar para SIMCE, entonces la sacan. ¡Claro! Hay un menosprecio. ]Y lo digo así, menosprecio [...] No va a venir un profesor de Música a decirte: "convídame una horita de Matemática porque tengo que practicar esto". No. Jamás. Pero, sin embargo, con esas asignaturas artísticas, se saca" (prof. 5, 23:43).

Las participantes manifiestan que durante el primer ciclo de EGB apenas se realiza un trabajo sistemático necesario para preparar al alumnado para el siguiente ciclo, llegando al final de la etapa con problemas de comprensión debido a información inconexa que no logra formar modelos mentales. Quizá influya en esto que la asignatura no es una materia evaluable en la prueba de madurez SIMCE, bajando la consideración de la misma a vista del sostenedor del centro, quien no le asigna suficientes recursos. Lo mismo ocurre con las horas de libre disposición o la propia asignación curricular de las horas de Música, que son utilizadas en otras materias evaluables.

En relación a los contenidos y a la praxis en educación musical, reconocen abiertamente las debilidades de su formación inicial, impidiéndoles desarrollar una labor adecuada en las clases. No suelen realizar montajes musicales con instrumentos, probablemente por falta de recursos en el aula o por ausencia de destrezas en este ámbito. Los contenidos que seleccionan suelen ser aquellos que les permiten realizan sus labores de reemplazo de la asignatura del modo más exitoso, bien porque no tienen tanta relación con los aspectos técnicos musicales (las debilidades que declaran), bien porque se encuentran más familiarizadas con esos contenidos. Tal es el caso de asociar la música con la "parte folclórica", o con "la parte de conocimiento y conexión con culturas anteriores" (prof. 1; 23:51), lo cual “a los chiquillos les motiva, porque esa parte allá sí se une con las otras asignaturas” (prof. 1,23:52). En general, seleccionan canciones como contenido fundamental, siempre en un contexto de "flexibilidad curricular" obligada por las competencias musicales de las profesoras:

“Cantamos todo el año. Nos encantamos con la música. Y después me decían los papás: "tía, qué linda la canción que les enseñó a los niños”. Seguimos cantando ¡Pues era mi única herramienta! Porque cantaban, veíamos el video, aprendían y ellos estaban felices con la música”. (prof.3, 23:64).

4 Las horas de libre disposición son horas lectivas libres de materias curriculares que el colegio asigna a actividades, proyectos o refuerzo disciplinar. 
"Yo sigo lo que dice el currículo, pero ahí veo según los cursos. Hay cursos que puedo pedirles flauta a todos los niños y me van a llegar con flauta, pero hay cursos que no. Entonces, ahí cambio la actividad, no puedo hacer lo que me dice el currículo. Me lo salto". (prof. 4, 23:69).

Otra profesora, que se siente musicalmente más apta que el resto de participantes, alude a la carencia de habilidades musicales y a la obligación de tener que responsabilizarse del desempeño en una materia en la que no están capacitadas y, que según sugiere, podría no gustarles:

\begin{abstract}
"Yo creo que hay mucho porcentaje de improvisación, de tener que sacar adelante y ser responsable y hacerlo. Dentro de esa improvisación podemos caer en que algunas personas tienen mayores capacidades o habilidades para la música [...] eso es lo lastimero, porque un profesor que no se siente identificado, que no siente relación con las artes, con esta parte del área artística, su actividad va a ser también baja”. (prof. 2, 23:135).
\end{abstract}

Sin embargo, a pesar de sus carencias técnicas, critican el enfoque lectoescritor de la didáctica que sus colegas especialistas de Educación Musical muestran en ocasiones:

“Con los profesores de música, también pasa lo mismo. No todos tienen la didáctica para llegar a cada niño. Así que igual de repente necesitan estrategias para acercar a los niños al lenguaje musical. Tal vez diversificar esa metodología. Porque yo, cuando a veces entro en la sala, veo la pauta [pentagrama]. Y veo la pauta, y ellos después tratando de sacar el sonido de ahí. No veo otra cosa. No hay otra forma parece de aprender". (prof. 5, 23:105).

El tiempo es un factor clave en la preparación de clases para estas profesoras. Mencionan que el programa de estudio ofrece sugerencias de actividades, pero la falta de tiempo en un horario laboral tan intensivo ${ }^{5}$ impide que puedan buscar material didáctico y preparar las clases de Música (prof. 5, 23:19, 23:99), lo que podría llevar a una despreocupación hacia la materia: "Imagínate: un uni-docente con 10 asignaturas. Es súper complicado, entonces uno empieza a dejarlo un poco de lado" (prof. 2, 23:20).

Respecto a la evaluación, las profesoras mantienen discrepancias durante el grupo focal sobre la pertinencia de la evaluación de aprendizajes musicales. Algunas, manifiestan utilizar instrumentos concretos, como listas de cotejo (listas de control), rúbricas o escalas de apreciación, hasta otros más generales, como el resumen de clase para evaluación del proceso. Una de ellas cree que la evaluación en Música no es pertinente, estableciéndose un debate sobre este asunto. Para ella, la participación del niño en la clase de música ya implica una evaluación positiva por el mero hecho de participar. Es por tanto una evaluación actitudinal, más que disciplinar. Discrepa la profesora 5, argumentando que los niños no deberían beneficiarse de calificaciones máximas por el solo hecho de considerarse materias "recreativas". Estas calificaciones máximas podrían facilitar el paso a estudiantes con calificaciones deficientes en materias "duras". Para ella, la evaluación no es tanto un proceso natural de la asignatura, como un proceso para evitar problemas con otras materias y tener un cierto control sobre la evaluación general del curso.

La profesora 5 parece entender que la Educación Musical podría disfrazar la evaluación del alumnado, equilibrando malos resultados de otras materias "menos recreativas", lo que, en su imaginario, podría ser impropio. Dicho de otra forma, parece entender que las materias "blan-

5 El profesorado chileno de EGB tiene una dedicación profesional a jornada completa entre 42 y 44 horas semanales, dependiendo del centro educativo. 
das" (Educación Artística) no son tan importantes como las materias "duras" (Matemáticas) y que aquellas no deberían relativizar la importancia de estas en la formación de escolares.

Respecto a la profesora que declara que no debe existir evaluación, es destacable su posicionamiento sobre la validez de la Educación Musical ¿por qué evaluar una materia si intrínsecamente es beneficiosa para el desarrollo del niño o de la niña? Dado que son "intrínsecamente buenas", las artes deberían constituir un núcleo especial dentro de la educación obligatoria que, por definición, se situaría fuera de lo evaluable (Ross, 1986). En este rechazo de la evaluación, también se argumenta la singularidad de las actividades artísticas en la educación (Hargreaves, 1991). Dada la tradición positivista, las artes se consideran materias de categoría inferior; sus resultados no se pueden cuantificar con herramientas habituales (Aspin, 1986); por tanto, la evaluación, en el mejor de los casos, es injustificable y difícil de realizar de acuerdo al paradigma dominante. A pesar de lo mencionado, las profesoras intentan ajustarse a una evaluación normalizada, aunque insisten en sus limitaciones en el área:

"No todos tenían siete $e^{6}$, había niños que tenían rojo, y también estaba sorpresa ¿̇y por qué un rojo en música?' ‘Esto tan fácil! En participación” (prof. 4, 23:115)

“... nuestra evaluación debe tener muchas falencias [debilidades] también en cuanto al criterio que aplicamos" (prof. 1, 23:117).

A las profesoras les preocupa la ausencia de recursos para la asignatura en sus salas de clases. Hay un consenso general sobre la falta de medios materiales, en algunos casos, insólito:

\footnotetext{
"Esta es una asignatura que necesita muchos recursos para que abarque para toda la cantidad de alumnos que un profesor pueda manejar [...] en el colegio donde yo estoy ahora, el profesor anda con una bolsita de género con 30 flautas. Y es la que va a pasando de curso en curso". (prof. 6, 23:48)

“. yo ando con mis parlantes [altavoces] porque sé que los del colegio no funcionan. Notebook [ordenador portátil] hay dos. Entonces yo ando con mi notebook, porque sé que alguna colega lo puede necesitar y yo me manejo mejor en mi computador. No hay data [proyector de vídeo] en las salas. Yo tengo que andar con el data”. (prof. 2, 23:136)
}

En relación a otros recursos, como las salidas pedagógicas a conciertos didácticos, manifiestan que son escasas y no se dan facilidades para realizarlas. En cuanto a las metodologías empleadas por las profesoras, usan generalmente enfoques prácticos de canto, audición y juegos musicales. En sus métodos de enseñanza, tratan de implicar a los alumnos en mecanismos afectivos más que cognitivos y en procedimientos más que conceptos, lo cual parece una aproximación correcta en dicha etapa. Es probable que este enfoque sea adoptado por la baja confianza en sus habilidades técnicas en Educación Musical, antes que por una filosofía consistente sobre la educación musical en la etapa, que no ha aflorado en ningún momento del grupo de discusión.

\section{Discusión}

El objetivo de este estudio inicial sobre el desempeño en educación musical del profesorado generalista chileno ha sido extraer una instantánea de una de las muchas realidades que se dan en la

6 Siete es la puntuación más alta en el sistema educativo chileno, siendo cuatro la nota de corte para superar una materia o curso. 
educación musical chilena a través de una interpretación de datos complementarios. Obviamente, no pretende generalizar los resultados, sino mostrar el imaginario de las profesoras sobre los temas tratados a través del grupo de discusión y triangular sus afirmaciones con otros datos de tipo cuantitativo.

Sus resultados sugieren que existe una inadecuada o incompleta formación musical del profesorado generalista de Chile que afecta a su desempeño profesional en la asignatura de educación musical. Estos coinciden con las conclusiones del estudio de Alter, Hays y O’Hara (2009) sobre desempeño del profesorado de materias artísticas en Educación Primaria. En él, los participantes mencionan que la cantidad y calidad de la formación inicial recibida no prepara adecuadamente para impartir educación artística y que incide directamente en la autoconfianza del profesorado. Esta falta de formación musical del profesorado generalista se evidencia a través del análisis documental de Ángel-Alvarado (2018a) sobre la formación inicial docente del profesorado de EGB, donde se menciona que un significativo número de universidades chilenas no imparte una formación musical inicial adecuada o pertinente al desempeño futuro del profesorado generalista. Asimismo, se alinean con los del estudio mixto de Orbeta-Green y Oyanedel-Frugone (2018), que demuestra la escasa implementación de materias artísticas en los planes de estudio de Pedagogía en EGB en 49 universidades chilenas.

El profesorado que llega a impartir clase de música lo hace generalmente por la obligación de completar su carga horaria, o bien por sustituciones provisionales debidas a licencias, que a veces se convierten en definitivas. Una gran parte de las personas afirman que les "gusta la música" y sus motivos son puramente altruistas, en general, porque la educación musical debe ser parte de la formación que han de recibir en la escuela. Aun cuando hayan tenido experiencias musicales previas, el profesorado generalista no es proclive a impartir educación musical, lo que coincide con el estudio de Alter, Hays y O'Hara, (2009).

Así pues, en los dos primeros ciclos de la Educación General Básica (EGB), el profesorado generalista llega a la materia sin ideas pedagógico-disciplinares sobre intervención en educación musical. El Ministerio de Educación de Chile (2018) tiene publicado unos Programas de Música para los seis primeros cursos de EGB que permite planificar la acción docente en Educación Musical. Sin embargo, aunque parezca paradójico, dos terceras partes de las personas encuestadas manifiestan no haberlos utilizado. Quizá esto es debido a que los Programas de Música para la EGB requieren conocimientos musicales que van más allá de la formación que recibió el profesorado en su carrera universitaria. Esta interpretación se triangula con las respuestas de las profesoras del grupo de discusión.

Respecto a los ejes del currículo que aparecen explícitos en los Programas de Música en EGB, la mayoría de actividades preferidas por el profesorado se incluyen en el eje Escuchar y Apreciar. Este resultado es plausible: la formación musical inicial del profesorado generalista parece ser escasa o limitada (Ángel-Alvarado, 2018a) y este eje les permite abordar audiciones sin las exigencias de conocimiento disciplinar que requiere el eje interpretar y crear o el eje reflexionar y contextualizar. No obstante, hay que tener en cuenta la alta abstención en la respuesta a este ítem, que va del $40 \%$ para los dos primeros ejes, al $24 \%$ para el segundo. Ello podría ser interpretado como 
que el profesorado no sigue estrictamente los ejes que marca el currículo de Música, adaptando o llevando a clase actividades que recoge de otras fuentes diferentes al programa. Esta interpretación se triangula con los datos obtenidos acerca de la procedencia de las actividades que propone el profesorado en la sala de clases, que muestran que un $57 \%$ del profesorado adopta actividades que provienen de libros, de Internet o de propia producción. Esto podría indicar también una falta de sistematicidad o de progresión de las actividades de enseñanza.

Asimismo, el profesorado llega a impartir música en EGB con una carencia generalizada de recursos en la sala de clases, sobre todo en infraestructuras e instrumentos, agravada quizá por la masificación de las aulas. Es habitual encontrar aulas con 40 niños en los colegios chilenos, lo que dificulta la provisión de recursos por parte del centro. Los datos obtenidos en el grupo de discusión se corroboran con los de una conversación informal mantenida con profesores de EGB (Tejada, 2018). En esta conversación, varios profesores coinciden que el principal problema al que se enfrentan es la cantidad de niños y la estrechez de los presupuestos, lo que provoca una insuficiencia de recursos no sólo para música, sino también para el resto de materias. Este problema parece ser común también al último ciclo de EGB y Enseñanza Media, según las manifestaciones obtenidas en una encuesta con ítems abiertos a una muestra de 15 profesores de educación musical, cuyos resultados no se muestran aquí (Tejada, 2018). Así se expresa una profesora con amplia experiencia docente en música: "Me encontré con varios ex-alumnos al cabo del tiempo impartiendo clases en colegio; siempre me manifestaban sus preocupaciones por la falta de recursos que tenían al momento de enseñar música" (prof. 1; 11:2).

No hay sala específica de educación musical en más de la mitad de los centros en que trabaja el profesorado participante. Este dato se triangula con los proporcionados por el informe de Bardone y Gargiulo (2014), en el que se discuten las condiciones físicas, ambientales y de confort que las escuelas deberían disponer a fin de proveer un entorno más apropiado, sustentable y saludable para logar un mejor desempeño, la permanencia escolar y la disminución de actos violentos entre estudiantes. Este estudio menciona trabajos que correlacionan positivamente un entorno apropiado (presencia de biblioteca, laboratorio de ciencias, salas de ordenadores, aulas de arte, aula de música) y los resultados académicos de alumnos del nivel primario en las pruebas estandarizadas SERCE (Segundo Estudio Regional Comparativo y Explicativo de América Latina y el Caribe) (Unesco, 2009). El trabajo constata que Chile no eligió la sala de Educación Musical como unidad funcional pedagógico-curricular esencial durante la elaboración del SERCE (p. 5). Asimismo, los autores recomiendan la implementación de dichos recursos en los centros educacionales de los países participantes.

Los resultados sobre carencia de recursos también coinciden con los resultados de ÁngelAlvarado y Lira-Cerda (2017). Junto a una formación inicial docente incompleta o inadecuada, esta podría ser otro motivo de que una tercera parte del profesorado generalista manifieste abiertamente que no le gusta dar clase de música.

Es preocupante para la educación musical chilena que más de una cuarta parte del profesorado encuestado manifieste la inexistencia de horas para Educación Musical en los dos primeros ciclos de EGB en sus centros. Este hecho es grave, pues la educación musical, conjuntamente con 
la educación artística, es obligatoria en el sistema educativo chileno. Este dato de encuesta se triangula con las manifestaciones de las profesoras del grupo de discusión: el profesorado de áreas como Matemáticas y Lenguaje solicita al profesorado generalista que les "cedan" horas de educación musical. Quizá algunos sostenedores de centros educativos permitan estas prácticas, valorando así más los resultados de la prueba nacional de aptitud SIMCE (materias evaluables) que la obligación de impartir Educación Musical: un bajo desempeño del centro educativo en dicha prueba implica una disminución en las matrículas, lo que lleva a una pérdida de financiamiento y a dificultades para mantener abierto el colegio, todas consecuencias graves que afectan directamente a profesores y alumnado. De hecho, son las pruebas estandarizadas las que obligan a las escuelas y sus profesores "a someterse a un currículum nacional progresivamente reducido y a modificar sus prácticas pedagógicas en función de estos estándares" (Flórez y Saldivia, 2014, p.2). La prueba SIMCE ha sido duramente criticada por algunos sectores educativos y académicos (Flórez, 2014; Ortiz, 2012), al igual que ha ocurrido en otros países con sus pruebas nacionales (Monarca y Fernández-Agüero, 2018). SIMCE debe su existencia a la reconsideración de la educación como bien de consumo en lugar de un derecho del ser humano, fenómeno surgido a raíz del proceso de privatización de la educación pública y posterior mercantilización de la educación en Chile a partir de 1982, con el auge del neoliberalismo, lo cual ha producido una fractura, sostenida y aumentada con el paso de los años, un fenómeno general en Latinoamérica (González y Parra, 2016).

Dos terceras partes del profesorado indagado no utiliza los Programas de Música para EGB que publica el Ministerio, sino que adapta o adopta actividades que proceden de Internet. Hacen uso predominante del eje Escuchar y Apreciar, frente a los otros dos ejes del currículo y evalúan de forma desestructurada los aprendizajes, principalmente a través de presentaciones de los alumnos. No obstante, existe una alta abstención de respuesta a estos ítems, lo cual podría indicar desatención a los aspectos técnicos de la materia, bien por falta de tiempo, por desinterés o por carencias en la formación pedagógica o disciplinar. No se han hallado indicios de ninguna de las dos primeras causas, pero existen indicadores de la última en la triangulación de los datos obtenidos en el grupo de discusión.

Esto evidencia la desarticulación entre la teoría curricular concretada en los planes de formación inicial docente y el desempeño docente (Ángel-Alvarado, 2018b). Asimismo, permite ver el sesgo del Ministerio de Educación de Chile, cuyos asesores y técnicos ponen énfasis en jerarquizar determinadas asignaturas (por ejemplo, Lenguaje y Comunicación, Matemáticas) en detrimento de las materias artísticas, atendiendo a políticas educacionales con estándares que parecen buscar más una instrucción en áreas específicas del saber que una educación integral, dejando al resto de materias al margen de las prioridades que las políticas de estado establecen.

Lo expuesto hasta aquí conformarían algunas de las razones del declive de la educación musical en la escuela mencionadas por Aróstegui (2016), es decir, un modelo de currículo consignado en las reformas educacionales, el énfasis en evaluaciones nacionales estandarizadas (SIMCE, END) y una menor disponibilidad de recursos para la educación musical. Todo ello afecta a las decisiones de las universidades respecto a los programas de estudio de formación inicial docente del 
profesorado de EGB que ofertan, mostrando disparidad e inadecuación (Ángel-Alvarado, 2018b; Orbeta-Green y Oyanedel-Frugone, 2018).

Como se avanzó anteriormente, estas inconsistencias son explicables desde un posicionamiento ideológico neoliberal, confirmando un énfasis en las materias relacionadas con la eficiencia y productividad económica. Se relega así a un segundo plano la potencialidad de las materias artísticas en relación a la creatividad y la capacidad de analizar la realidad desde códigos únicos (Belletich, Wilhelmi y Ángel-Alvarado, 2016). Sin embargo, el neoliberalismo ha visto fracasados sus objetivos de mitigar la crisis del capitalismo desde la década de los setenta a través de estrategias como la globalización, la desregulación y la flexibilización (Gandásegui, 2009). Es deseable que a medida que el sistema neoliberal colapse y entren en juego políticas más equitativas, menos individualistas y más sociales, los actores del sistema educativo chileno favorezcan los cambios necesarios para que se acceda no solo a una formación consistente e integral en educación musical, sino al acceso gratuito a una educación de calidad. Porque la educación debe ser un bien público (Locatelli, 2018).

\section{Agradecimientos}

Este trabajo ha sido financiado por el Programa de Atracción de Capital Humano Avanzado Extranjero, Consejo Nacional de Investigación, Ciencia y Tecnología, Gobierno de Chile (CONICYT, PAI80160102). Gracias a Marcela Oyanedel, Tania Ibáñez y Claudio Merino, del Dto. de Música de la Universidad de Chile, por su participación activa en este proyecto.

\section{Referencias}

Abrahams, F. (2005). The application of critical pedagogy to music teaching and learning. Visions of Research in Music Education, 6, 1-16. Recuperado de: http://www.rider.edu/ vrme

Agencia de Calidad de la Educación (2018). Resultados Educativos 2017. Recuperado de: http:// archivos.agenciaeducacion.cl/Region_Metropolitana_2017.pdf

Alter, F., Hays, T., y O'Hara, R. (2009).Creative arts teaching and practice: critical reflections of primary school teachers in Australia. International Journal of Education and the Arts, 10(9), 1-21. Recuperado de: https://eric.ed.gov/?id=EJ859040

Ángel-Alvarado, R., y Lira-Cerda, P. (2017). Instalaciones y recursos educativos para la educación musical, según la representación social de los estudiantes chilenos. Revista Electrónica de LEEME, 40, 19-31. doi: 10.7203/LEEME.40.10412

Ángel-Alvarado, R. (2018a). Formación inicial del profesorado general en Chile: análisis desde la perspectiva de la educación musical. REDU Revista de Docencia Universitaria, 16(1), 87101. Recuperado de: http://bit.ly/2lNgDDQ

Ángel-Alvarado, R. (2018b). Controversias entre la teoría curricular y la práctica educativa en la educación musical. Revista Electrónica Complutense de Investigación en Educación Musical, 15, 83-95. doi: 10.5209/RECIEM.58530 
Aróstegui, J. L. (2016). Exploring the global decline of music education. Arts Education Policy Review, 117, 2. 96-103. doi: 10.1080/10632913.2015.1007406

Aspin, D. (1986). Objectivity and assessment in the arts: the problem of aesthetic education. En M. oss (Ed.), Assessment in arts education. Oxford: Pergamon Press.

Bardone, A., y Gargiulo, C. (2014). Aprendizaje en las escuelas del siglo XXI: Nota 6, normas y costos. Washington: Banco Interamericano de Desarrollo. Recuperado de: http://bit. ly/2IUZ3xt

Bautista, P. (2017). El futuro maestro generalista ¿preparado para utilizar la música en su enseñanza? Educación y Ciencia, 6(47), 32-44. Recuperado de: http://bit.ly/21PL782

Belletich, O., Wilhelmi, M., y Ángel-Alvarado, R. (2016) La educación musical en la formación básica en España. El problema de la dispersión curricular. Perspectiva Educacional, 55 (2), 158-170. Recuperado de: http://bit.ly/2kz7XRj

CPEIP (2018). Oferta de cursos de formación continua. Recuperado de: http://bit.ly/2kIXFOg

Coffey, A., y Atkinson, P. (2003). Encontrar el sentido a los datos cualitativos. Antioquía: Editorial Universidad de Antioquía. Recuperado de: http://bit.ly/21SV7O4

De Vries, P. (2011). The first year of teaching in Primary school: Where is the place of music? International Journal of Education and the Arts, 12(2), 1-25. Recuperado de: https://files. eric.ed.gov/fulltext/EJ937063.pdf

De Vries, P. (2013). Generalist teachers' self-efficacy in primary school music teaching. Music Education Research, 15(4), 375-391. doi: 10.1080/14613808.2013.829427

Efland, A. (2004). Arte y cognición. Barcelona: Octaedro-EUB.

Eisner, E. (2002). El arte y la creación de la mente. Barcelona: Paidós.

Flórez, M.T. (2014). El problema es el SIMCE: una mirada histórica, ideológica y técnica. El Mostrador (13-06-2014). Recuperado de: http://bit.ly/2kl8k1E

Flórez, M.T., y Saldivia, S. (2014). El SIMCE: Una herramienta sin sentido para la educación en Chile. Ciper (19-02-2014) Recuperado de: http://bit.ly/2kJLKQo

Gandásegui, M.A. (2009). El fin del neoliberalismo y la crisis económica. Recuperado de https:// www.alainet.org/es/active/32842

Garvis, S. (2013). Beginning generalist teacher self-efficacy for music compared with maths and English. British Journal of Music Education, 30(1), 85-101. doi: 10.1017/S0265051712000411

Gifford, E. (1993). The musical training of primary teachers: Old problems, new insights and possible solutions. British Journal of Music Education, 10, 33-46. doi:10.1017/S0265051700001418

González, J., y Parra, D. (2016). Mercantilización de la educación. Comentarios sobre la reforma educativa en Chile 2015. Enfoques Educacionales, 13(1), 71-89. Recuperado de: https://revistas.uchile.cl/index.php/REE/article/view/44633/46650

Hallam, S., Burnard, P., Robertson, A., Saleh, C., Davies, V., Rogers, L., y Kokatsaki, D. (2009). Trainee primary-school teachers' perceptions of their effectiveness in teaching music. Music Education Research, 11(2), 221-240. doi: /10.1080/14613800902924508.

Hargreaves, D. (1991) La psicología evolutiva y las artes. En D. Hargreaves (Ed.), Infancia y 
educación artística. Madrid: Morata.

Holden, H., y Button, S. (2006). The teaching of music in the primary school by the non-music specialist. British Journal of Music Education, 23(1), 23-38. doi:10.1017/S0265051705006728

Jeanneret, N. (1997). Model for developing preservice Primary teachers' confidence to teach music. Bulletin of the Council for Research in Music Education, 133, 37-44. Recuperado de: http://bit.ly/2lUV2ZS

Locatelli, R. (2018). La educación como bien público y común. Reformular la gobernanza de la educación en un contexto cambiante. Perfiles educativos, 40(162), 178-196. Recuperado de http://bit.ly/31IzhvV

Mills, J. (1989). The generalist primary teachers of music; a problem of confidence. British Journal of Music Education, 6(2), 125-138. doi: 10.1017/S0265051700007002.

Ministerio de Educación de Chile (2012a). Bases curriculares de Educación Básica. Recuperado de: http://bit.ly/2mgXM4c

Ministerio de Educación de Chile (2012b). Estándares orientadores para egresados de carreras de Pedagogía en Educación Básica. Recuperado de: http://bit.ly/2lPOk7A

Ministerio de Educación de Chile (2017). Prueba de Evaluación Nacional Diagnóstica. Recuperado de: https://www.cpeip.cl/formacion-inicial-docente/

Ministerio de Educación de Chile (2018). Curriculum en línea. Recuperado de: https://www. curriculumenlineamineduc.cl/605/w3-propertyvalue-52051.html

Monarca, H., y Fernández-Agüero, M. (2018). Opinión del profesorado sobre las fortalezas y debilidades de las evaluaciones externas de aprendizaje en España. Educación XX1, 2(2), 249-273. doi: 10.5944/educXX1.19416

Orbeta-Green, A., y Oyanedel-Frugone, R. (2018). En vías de desaparición. Antecedentes para entender la disminución de las artes en la formación inicial docente de educación primaria en Chile. Arte, Individuo y Sociedad, 30(2), 375-394. doi: 10.5209/ARIS.57622

Oreck, B. (2004). The artistic and professional development of teachers: a study of teachers' attitudes toward and use of the arts in teaching. Journal of Teacher Education, 55, 55-69. doi: $10.1177 / 0022487103260072$

Ortiz, I. (2012). En torno a la validez del Sistema de Medición de la Calidad de la Educación en Chile. Estudios Pedagógicos, 38(2), 355-373. Recuperado de: http://bit.ly/2lQP3W7

Regelski, T. A. (2005). Critical theory as a foundation for critical thinking in music education. Visions of Research in Music Education, 6, 1-23. Recuperado de: http://www.rider.edu/ vrme

Ross, M. (1986). Against assessment. En M. Ross (Ed.), Assessment in arts, pp. 83-89. Oxford: Pergamon.

Russell-Bowie, D. 2011. 'An ode to joy ... or the sounds of silence? An exploration of arts education policy in Australian primary schools. Arts Education Policy Review, 112(4), 163-173. doi:10 $.1080 / 10632913.2011 .566099$

Sepúlveda, L. (2014). Políticas comparadas de educación artística: pistas para una nueva institucionalidad del sistema educacional en Chile. Actas de la II Semana de Educación Artística (Santiago, 12-16 de mayo, 2014). Recuperado de: http://bit.ly/2keEmw4 
Tejada, J. (2018). Comunicación personal obtenida del profesorado asistente al curso de formación musical EFORMUS (Recoleta, Santiago de Chile; 31-8-2018).

Torres, J., y Perera, V. (2009). Cálculo de la fiabilidad y concordancia entre codificadores de un sistema de categorías para el estudio del foro online en e-learning. Revista de Investigación Educativa, 27(1), 69-103. Recuperado de: http://revistas.um.es/rie/article/view/94291

Unesco (2009). SERCE: Segundo estudio regional comparativo y explicativo. Los aprendizajes de los estudiantes de América Latina y el Caribe; reporte técnico. Santiago: Orealc-Unesco. Recuperado de: http://bit.ly/2mgYY7G

\section{Anexo: Cuestionario}

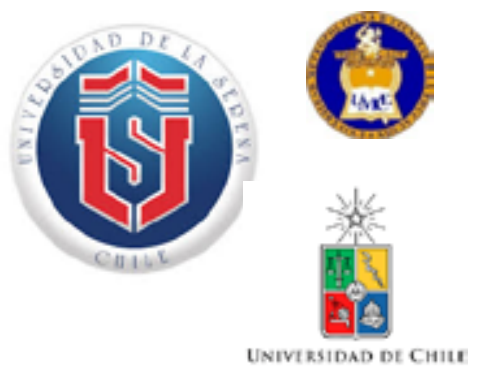

PROYecto "Plataformas digitales Para la ED. MUSICAL" (EDUCAMUS)

(Programa de Atracción de Capital Humano Avanzado. COnicyt. FOLIO PAI80160102)

Este cuestionario anónimo se dirige al profesorado de Educación General Básica en centros educacionales municipales y subvencionados chilenos que imparten la materia Música en los dos primeros ciclos de Ed. Básica. Asimismo, se dirige al profesorado de Ed. Parvularia que imparten música en sus establecimientos educacionales. Sus objetivos son: Conocer datos y percepciones acerca de: 1) su período de formación inicial docente y necesidades formativas, 2) su praxis docente y necesidades en la asignatura Música en Ed. Básica, 3) sus percepciones sobre la tecnología en la formación continua de los docentes. El objetivo último del estudio es elaborar una plataforma online de formación musical continua para profesores no especialistas de música basada en la detección de sus percepciones y necesidades. Este estudio ha sido financiado por CONICYT a través del Programa de Atracción de Capital Humano Avanzado Extranjero, modalidad Estadías Cortas (PAI80160102) y está siendo ejecutado por Universidad de La Serena. Universidad Metropolitana de CC. de la Educación y U. de Chile. Los resultados obtenidos se utilizarán para investigación y comunicación científica. En la parte de investigación, como se ha mencionado, los datos servirán para establecer la arquitectura software de una plataforma de formación continua del profesorado de Ed. Básica y Ed. Parvularia. A su vez, esta estructura servirá para la implementación de dicha plataforma, que será evaluada a través de su puesta en funcionamiento. Para ejercer su derecho a retracto o a recuperación de información o de resultados de este trabajo, escriba a esta dirección de correo electrónico: marenas@userena.cl

Asimismo, le informamos que se han adoptado las medidas oportunas para garantizar la completa confidencialidad de los datos personales de los y las participantes en este estudio, de acuerdo con 
la Ley De Protección de Datos de Carácter Personal (Ley 19.628).

Se ha establecido un sistema de anonimización efectivo que no permite la identificación posterior de las personas participantes. En ningún caso se juntarán los consentimientos otorgados, donde sí se identifica al sujeto, con los cuestionarios utilizados en el estudio. En el uso que se realice de los resultados del estudio, con fines de docencia, investigación y/o publicación, se respetará siempre la debida anonimización de los datos de carácter personal, de modo que las personas no resultarán identificadas o identificables. Al cumplimentar esta encuesta, Ud. está consintiendo en participar en esta investigación. Por ello, EL EQUIPO DE INVESTIGACIÓN AGRADECE SINCERAMENTE SU PARTICIPACIÓN

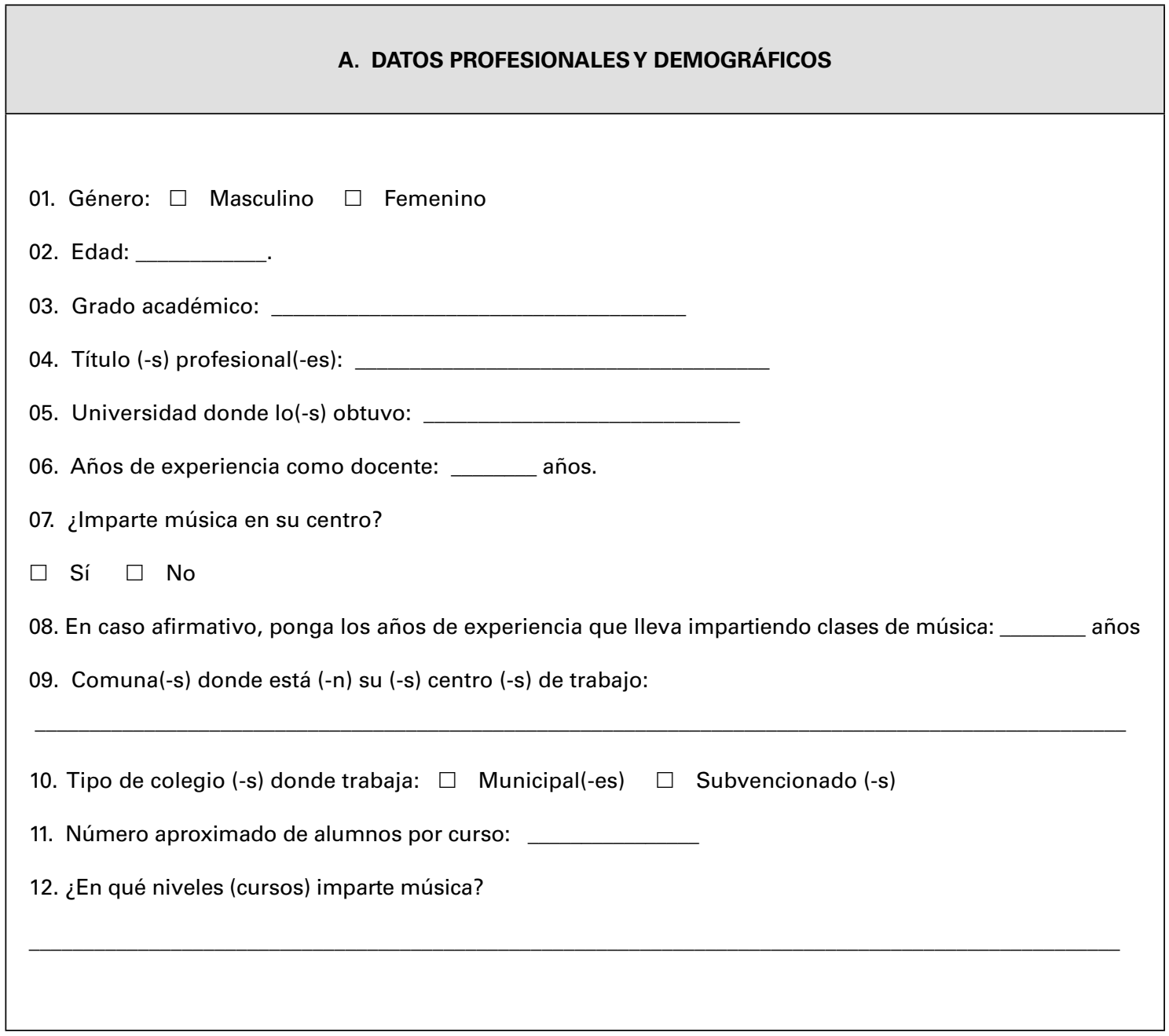




\section{B. FORMACIÓN MUSICALY NECESIDADES FORMATIVAS}

13. ¿Antes de su formación universitaria como profesor de educación básica tuvo experiencias musicales previas?

$\square$ Sí $\square$ No

14. En caso afirmativo, escriba de qué tipo (participación en coro; participación en un grupo musical, ejecución de algún instrumento como aficionado(a); estudios formales de música; clases particulares; etc.).

15. ¿Tuvo cursos de formación musical en su carrera?

$\square$ Sí $\square$ No

16. En caso afirmativo, marque la(s) alternativas que mejor describan las asignaturas musicales cursadas en su carrera, indicando al lado derecho la duración de estas:

$\square \quad$ Lectura Musical (Teoría y Solfeo) semestre(-s)

$\square \quad$ Instrumento musical

$\square$ Danza

$\square$ Expresión corporal semestre(-s) ¿Cuál?

$\square$ Folclore semestre(-s)

$\square$ Didáctica (pedagogía) musical semestre(-s) semestre (-s)

Otra. Especificar:

17. ¿Qué cursos de formación musical continua ha realizado?

Respuesta:

18. ¿Qué tipo de curso de formación continua sobre música cree que Ud. necesitaría para un mejor desempeño? (puede marcar ambos, uno o ninguno de ellos).

$\square$ Cursos de formación musical

$\square$ Cursos de formación pedagógica en música

$\square$ Otros (especificar)

19. ¿Le facilita el sostenedor tiempo para su formación continua en música?

$\square$ Sí $\quad \square$ No

20. ¿El sostenedor incluye el tiempo de formación continua dentro de su jornada de trabajo?

$\square$ Sí $\quad \square$ No

21. ¿El sostenedor le apoya económicamente en su perfeccionamiento docente?

$\square$ Sí $\quad \square \quad$ No

22. Cree que existe una suficiente oferta formativa que responda a sus necesidades de perfeccionamiento en música?

$\square$ Sí $\quad \square$ No

23. En caso negativo, ¿qué tipo de cursos de formación musical le interesaría? 


\section{RECURSOS MUSICALES DEL COLEGIO}

24. ¿Cuántas horas de música semanales hay en su establecimiento? horas

25. Su establecimiento ¿cuenta con un profesor especialista de música?

$\square$ Sí

$\square \quad$ No

26. ¿Existe una sala exclusiva para la clase de música en su colegio?

$\square$ Sí

$\square \quad$ No

27. Marque en el cuadro correspondiente los recursos materiales de apoyo existen para impartir la clase de música en su colegio. En caso pertinente, marque con una cruz la frecuencia con que los utiliza

$\begin{array}{llll}\square & \text { Equipo de audio } & \text { nunca } & \text { a veces } \\ \square & \text { Pizarra digital } & - & - \\ \square & - & - \\ \square & - & - \\ \square & - & - \\ \square & - & -\end{array}$

\section{PRÁCTICA DOCENTE EN MÚSICA}

28. ¿Usa el programa de música vigente?

$\square$ Sí $\quad \square$ No

29. En caso de contestar que sí ¿Cuántas actividades de música del programa MINEDUC realizó con su curso? actividades

30. valore la utilidad de las actividades de dicho programa para las clases de música
$\square \quad$ Nada
$\square \quad$ Algo
$\square$ Regular
$\square \quad$ Bastante
Mucho

31. Valore la utilidad de las sugerencias metodológicas
$\square \quad$ Nada
$\square$ Algo
$\square$ Regular
$\square$ Bastante
Mucho

32. Valore la utilidad de las sugerencias de evaluación
$\square \quad$ Nada
Algo
Regular
$\square$ Bastante
Mucho 
33. De acuerdo a los siguientes ejes formativos, indique el grado de presencia de cada uno de ellos en la clase de música

Mucha Mediana Poca

$\square$ escuchar y apreciar

$\square \quad$ interpretar y crear

$\square$ reflexionar y contextualizar

$\square$ desarrollo de actitudes

34. ¿Utiliza la computadora y software asociado en algún momento para dar clase de música?

$\square$ Sí $\quad \square \quad$ No

35. En caso afirmativo, mencione algunas actividades que realiza con la computadora en la clase de música:

36. Qué tipo de actividades realiza mayoritariamente con los alumnos

$\square$ más teóricas que prácticas $\quad \square$ más prácticas que teóricas $\quad \square$ procura equilibrar ambos tipos

37. Al realizar las actividades con sus estudiantes ¿logra realizar una reflexión después de la actividad?

$\square$ Sí $\quad \square$ No

38. Las actividades que realiza con los alumnos:

$\square$ proceden de libros, Internet y otras fuentes $\square$ son diseñadas en su mayoría por Ud. $\square$ ambas procedencias

39. Cómo están dispuestos los alumnos en el aula cuando imparte música:

$\square$ en filas $\square$ en círculo $\square$ el curso se adapta en función de la actividad a realizar

$\square$ Otra forma (especificar)

40. Cómo evalúa el trabajo musical de sus estudiantes

$\square$ a partir de grabaciones

$\square$ prueba escrita

$\square$ a partir de presentaciones

$\square$ registros

$\square$ otros (indicar)

41. ¿Le gusta impartir música en la educación básica?

$\square$ Sí $\quad \square$ No

42. ¿Por qué?

43. ¿Por qué razón imparte música en su colegio? 